\title{
CONSTRUINDO INSTRUMENTOS DE EDUCAÇÃO POPULAR JUNTO A UM ACAMPAMENTO SEM TERRA*
}

\author{
Katia I. Marro \\ Daniel Francisco de Souza Santos \\ Deborah Minatelli de Oliveira \\ Clara Andrade Pereira \\ Letícia Santos Pinheiro
}

\section{Introdução}

\begin{abstract}
"Passagem do saber ao compreender, ao sentir, e, vice-versa, do sentir ao compreender, ao saber. O elemento popular 'sente', mas nem sempre compreende ou sabe; O elemento intelectual 'sabe', mas nem sempre compreende $e$, menos ainda, 'sente'. [...] $O$ erro do intelectual consiste em acreditar que se possa saber sem compreender e, principalmente, sem sentir e estar apaixonado (não só pelo saber em si, mas também pelo objeto do saber) [...]" (Gramsci, 1999, p. 221).
\end{abstract}

Este capítulo retrata e socializa a experiência de criação de um jogo didático a partir de um trabalho de campo proposto por uma disciplina de graduação em Serviço Social em articulação com um acampamento do Movimento dos Trabalhadores Rurais Sem Terra (MST). Fruto da troca de saberes entre sujeitos que lutam pela terra e estudantes e docentes da Universidade Pública, nasce o Jogo Territórios Agroecológicos que reúne conhecimentos da cultura e da identidade Sem Terra. Exercitando a dimensão socioeducativa do Serviço Social, ensaiamos a construção de um instrumento de educação popular capaz de dialogar com as estratégias de organização coletiva construídas pelo acampamento, no contexto da luta pela terra.

Os caminhos percorridos na disciplina Movimentos Sociais e Educação Popular do Curso de Serviço Social da Universidade Federal Fluminense do Campus Universitário de Rio das Ostras $^{1}$, buscaram recriar princípios educativos que rompessem com perspectivas bancárias ou autoritárias do conhecimento. Foi assim que decidimos construir um instrumento de educação popular - um jogo didático junto ao acampamento Edson Nogueira do MST, localizado no município de Macaé, Rio de Janeiro, onde também funciona uma Unidade Pedagógica em Agroecologia. Neste território, além das famílias que o habitam, existem experiências de formação política construídas em parceria com as Universidades Públicas da região.

Vem! Entre na experiência do Jogo Territórios Agroecológicos. Deixe-se tomar pelos seus dilemas, se encante com as suas riquezas, se inspire nas suas resistências!

\footnotetext{
"DOI - 10.29388/978-65-86678-92-5-0-F.31-46

${ }^{1}$ Trata-se de uma disciplina obrigatória da grade curricular e refere-se a uma experiência realizada no 10 semestre de 2019, como parte do processo de avaliação proposto.
} 


\section{De que território estamos falando?}

Como nasce a ideia do Jogo? A experiência de formação proporcionada pela disciplina nos instigou em diversas direções: revisitamos a história da organização de movimentos clássicos dos trabalhadores que lutaram por direitos que hoje constituem importantes políticas de proteção social; aprendemos a valorizar processos de autorganização de variados grupos subalternos contemporâneos que nas suas práticas prefiguram potenciais direitos; exercitamos a capacidade de reconhecer traços de luta e resistência que perpassam boa parte das expressões da questão social que demandam a intervenção de assistentes sociais e outros profissionais que atuam na implementação das políticas sociais.

Queríamos que os conteúdos trabalhados ao longo da disciplina se materializassem em alguma atividade ou intervenção nos territórios e espaços de organização popular característicos da região, onde também acontecem projetos de extensão e parcerias importantes com a nossa Universidade. Inicialmente, nos reunimos com representantes do MST e do acampamento em virtude de conhecer a disponibilidade e interesse das/os acampadas/os, ouvindo expectativas em relação à nossa aproximação. Deste encontro resultou a proposta conjunta de elaboração de um jogo cujo objetivo seria que funcionasse como um instrumento pedagógico para uso permanente das/os acampadas/os e educandas/os da Unidade Pedagógica, que auxiliasse os processos de formação política. No diálogo conjunto, fomos amadurecendo sobre a importância de que este instrumento dialogasse com a organicidade do MST; reunisse conhecimentos, vivências e valores centrais à experiência da luta pela terra e à produção agroecológica; e enriquecesse os momentos culturais e de construção identitária dessa comunidade. Surge assim a ideia inicial do jogo: deveria ser um jogo grupal que permitisse a participação de adultos e crianças; os ganhos e as perdas seriam coletivas e não estariam atreladas necessariamente ao prejuízo dos outros grupos que jogam; apareceriam datas e símbolos importantes para a história da luta pela terra; deveriam estar representados outros territórios de Reforma Agrária que existem na região (como o Assentamento Osvaldo de Oliveira), ou comunidades e favelas que também denunciam a falta de acesso a melhores condições de vida. Identificamos também que seria importante que o Jogo fosse iniciado pelo trabalho da disciplina, mas deveria ser finalizado no acampamento para reunir os saberes que nascem da experiência. A troca de saberes foi tão rica que tecemos a muitas mãos um nome: assim nasceu o Jogo Territórios Agroecológicos.

Seria necessário, então, uma preparação prévia da turma aproximando-se de diversos temas que atravessam as lutas em torno da Reforma Agrária, mas também do universo de significados da experiência de construção de um acampamento que luta pelo acesso à terra e a um conjunto de direitos sociais fundamentais. Em grupos, empreendemos uma pesquisa em torno de alguns temas sobre os quais que o MST tem uma importante elaboração para ampliarmos o referencial teórico e consolidar as bases metodológicas que fundamentariam a construção do jogo: educação; 
história da luta pela terra; reforma agrária e agroecologia; identidade Sem Terra; e mística foram alguns dos assuntos pesquisados ${ }^{2}$.

Teríamos o desafio de colocar em prática alguns conhecimentos aprendidos ao longo da disciplina, mas também de ensaiar o exercício da dimensão pedagógica do Serviço Social, num espaço diferenciado aos tradicionais equipamentos de políticas públicas. O jogo seria produto de uma troca de saberes diversos, que deveriam se materializar na produção de um instrumento que reunisse cultura; vivências; conhecimentos que nascem da experiência da luta pela terra, mas também de uma Universidade socialmente referenciada. Tal como nos alertara Gramsci (1999), as massas raciocinam com a experiência, "sabem" empiricamente, "sentem", mas não necessariamente tiram todas as consequências de uma determinada situação histórica (Dias in Del Roio, 2017, p. 72-73). E nada mais importante para o processo de formação de um profissional, de um/a docente ou pesquisador/a, de um intelectual, que se interrogar pela utilidade social dos conhecimentos produzidos à luz de experiências concretas que lhe demandem esse esforço de mediação.

\section{Para iluminar a reflexão}

Quais foram os debates teóricos que subsidiaram a nossa experiência? Impossível estudar e pesquisar as lutas sociais das classes subalternas, sem deixar de se impregnar pela radical vivência democrática que algumas das suas práticas pedagógicas encarnam. Exercitar uma práxis educativa que combinasse diversos saberes e vivências teórico-práticas; reflexões rigorosas sobre a realidade, mas reelaboradas a partir da experiência e do sentir popular (Ouviña, 2012), nos remetem inevitavelmente, aos aportes de Gramsci (1999, p. 96):

Criar uma nova cultura não significa apenas fazer individualmente descobertas 'originais'; significa também, e sobretudo, difundir criticamente verdades já descobertas, 'socializá-las' [...] transformá-las em base de ações vitais, em elemento de coordenação e de ordem intelectual e moral.

Gramsci rejeita a experiência do conhecimento como "descoberta individual", convidando-nos a valorizar seus impulsos democráticos e de liberdade, sua ancoragem coletiva.

Não é por casualidade que nas propostas formativas de inúmeros movimentos populares da América Latina, se observam continuidades entre esta radical vocação democrática e a perspectiva da educação popular presente nas elaborações de Paulo Freire. Mesmo reconhecendo as diferenças das suas tradições teóricas, há aqui um ponto possível de diálogo que inspirou a construção deste instrumento pedagógico ${ }^{3}$.

\footnotetext{
${ }^{2}$ Cf. Caldart (2004); Morissawa (2008); Bogo (2012); Freire (2012); Grein (2015); Mazin; Estevam; Stedile (2016).

${ }^{3}$ Inúmeros intelectuais que trabalham ou pesquisam experiências de educação popular junto a movimentos sociais identificam essa possível interlocução. Apenas para mencionar alguns que trabalhamos neste artigo: Ouviña (2012); Semeraro (2013); Mayo (in Del Roio, 2017).
} 
Freire (1987) nos fala de uma educação problematizadora e nos alerta de que o ato educativo não pode se reduzir a uma transmissão de conteúdos petrificados como retalhos da realidade que se "depositam" numa operação quase "bancária" ${ }^{4}$; desconexos; alheios à existência das/os educandas/os. Pelo contrário, deve proporcionar processos de busca para desvendar a realidade, deve promover atos criativos e de reinvenção.

Esta perspectiva é fundamental para pensar o processo de formação dos Assistentes Sociais, porque a/o educanda/o não pode ser um/a expectador/a que memoriza conteúdos abstratos, a riscos de reproduzir uma posição de passividade que seria um contrassenso ao nosso projeto de profissão. Por sua vez, esta perspectiva nos aponta questões importantíssimas para qualificar o vínculo que estabelecemos com os segmentos subalternos que se tornam usuárias/os dos equipamentos nos quais trabalhamos: uma palavra "oca" que se torna mais som que significação seria incapaz de enfrentar a cultura da dominação; desvelar a violência presente em toda relação de opressão; convidar à superação de uma posição de passividade ou estimular à criticidade, tal como nos instiga Freire na sua Pedagogia do Oprimido. Enquanto a educação bancária "assistencializa", a educação problematizadora "criticiza" (Freire, 1987, p. 41).

Estas referências teóricas nos desafiaram a promover relações de ensinoaprendizagem que envolvessem a criação coletiva e a socialização de saberes de natureza diferenciada, buscando estimular no ato educativo a vivência da crítica e da problematização.

Gramsci nos ofereceu também algumas referências para aprender a valorizar os saberes populares que emergem da prática histórica e dos processos de organização dos subalternos. Gramsci "mergulha" na ideologia das classes subalternas, destacando aspectos contraditórios nas formas como estas constroem sua identidade de classe; interrogando o significado da cultura popular e do folclore; da religiosidade; da linguagem; dos "elementos da psicologia popular"; ou "as aspirações mais elementares e profundas dos grupos subalternos" (Gramsci, 2002, p. 143). Vai "vasculhar" expressões do conformismo social nos hábitos, costumes, nas ideias fragmentadas que consolidam o exercício da hegemonia das classes dominantes (Schlesener in Del Roio, 2017). Ao reconhecer que "o elemento popular sente, mas nem sempre compreende" (Gramsci, 1999, p.221), Gramsci valoriza os ensaios pedagógicos e autoeducativos que os movimentos das classes subalternas empreendem, na direção de promover o progresso intelectual das massas através de uma reforma intelectual e moral capaz de desfazer os mecanismos que as subalternizam. Sua obra nos sensibilizou no sentido de resgatar as relações pedagógicas e as práticas educativas que os movimentos populares constroem na sua atuação:

\footnotetext{
${ }^{4}$ Neste modelo de educação "[...] a única margem de ação que se oferece aos educandos é de receberem os depósitos, guardá-los e arquivá-los. Margem para serem colecionadores ou fichadores das coisas que arquivam [...] o saber é uma doação dos que se julgam sábios aos que julgam nada saber" (Freire, 1987, p.33).
} 
As práticas políticas são, portanto, profundamente pedagógicas, porque implicam uma batalha hegemônica, um intercâmbio, uma aprendizagem mútua, uma metamorfose educativo-cultural pelos setores subalternos que fortalecem a sua autonomia por meio da organização (Ouviña, 2012, p. 11).

A vivência do jogo nos permite refletir sobre os processos de formação de consciência ${ }^{5}$, construídos pelos movimentos sociais, como parte dessas tentativas de elevação intelectual e cultural das massas na direção da sua expressão autônoma e antagônica na luta pela hegemonia (Del Roio, 2017).

Maria Izabel Grein (2015), intelectual e educadora destacada do MST, nos mostra algumas pistas acerca do processo de formação da consciência das/os trabalhadoras/es rurais na gênese do MST. Na trajetória histórica deste movimento, os primeiros enfrentamentos se deram pela sua necessidade de lutar por melhores condições de vida, num contexto marcado pelo acirramento da miséria, a violência do latifúndio e as expulsões em massa das suas terras, nos marcos da ditadura empresarial militar (1964-1985) que intensificava as contradições entre as classes. Mas é a partir da experiência da coletividade que a consciência da luta se eleva, definindo os rumos que o movimento social construirá no enfrentamento à grande propriedade privada no campo e colocando o direito à terra como um elemento central para estes segmentos. Para esta intelectual, a consciência alcançada no processo da luta se materializa nas conquistas e territórios organizativos, mas também está presente nos símbolos, nas representações, nas palavras de ordem, poemas e canções do MST, instrumentos que recriam a identidade de classe que fermenta nas suas lutas. Estes elementos nos apontavam aspectos do universo de sentidos que deveriam estar presente no instrumento pedagógico que estávamos propondo.

$\mathrm{Na}$ busca de trazer estas questões para pensar a atuação profissional das/os Assistentes Sociais, damos visibilidade à dimensão política da prática profissional e sua relação com as atividades de cunho socioeducativo. Construímos esta experiência como parte das estratégias possíveis para afirmar outra dimensão pedagógica para o Serviço Social - emancipatória, nos termos de Abreu \& Cardoso (2009) -, em diálogo com os processos de organização popular empenhados na construção de uma nova hegemonia social. De acordo com estas autoras, a mobilização social e organização são elementos fundamentais para a concretização de práticas educativas e, estas, vinculam-se a distintos projetos profissionais e societários. Tendo como referência um posicionamento ético-político vinculado às reivindicações e interesses das massas subalternas, a prática educativa executada:

\footnotetext{
${ }^{5}$ Em diálogo com a abordagem de lasi (2004 e 2011), no trabalho de Monteiro (2018) observamos um esforço importante de conceptualização a partir da teoria social crítica, identificando os processos de formação política e as experiências de educação popular como instrumentos que permitam a apropriação de conhecimentos capazes de oferecer uma leitura crítica e reflexiva da realidade, suas causas e determinações, produzindo formas de consciência social orientadas para o fortalecimento da organização política das classes trabalhadoras no horizonte da luta pela emancipação humana.
} 
Direciona-se para o fortalecimento dos espaços de luta dessas classes, onde é possível gerar e socializar conhecimentos, constituindo sujeitos coletivos capazes de participar da construção da hegemonia das referidas classes (Abreu \& Cardoso, 2009, p. 603).

No percurso experimentado na disciplina, o processo de produção do jogo deveria dialogar com as estratégias de luta pela terra protagonizadas por estes sujeitos, compreendendo e dialogando com reivindicações que se relacionam com o processo de conquista de direitos e políticas públicas, materializando assim um dos compromissos importantes do nosso projeto profissional. Por meio desta ação socioeducativa construída em conjunto com os acampados do MST que lutam pela Reforma Agrária Popular ${ }^{6}$, o jogo deveria reunir e transmitir conhecimentos sobre a terra e o cuidado com ela; formas de cultivo de alimentos; controle de pragas; instrumentos de organização ou mecanismos de negociação com o poder público para a garantia de direitos; além de possibilitar a vivência de valores como compromisso, solidariedade, trabalho coletivo, através de uma experiência lúdica. Assim estávamos, crianças, idosos, mulheres e homens, agricultores, estudantes e professores, pessoas LGBTs, negras e negros, trabalhadores, em suas mais diferentes formas de ser e (r)existir, jogando nos "Territórios Agroecológicos", aprendendo e ensinando. Enquanto sujeitos protagonistas de sua história, desorganizando e dissolvendo estratégias de apaziguamento que interditam a vivência da luta e da solidariedade de classe, organizando caminhos comuns e coletivos que prometem a conquista da terra, a moradia, a alimentação saudável e a educação em territórios da reforma agrária construídos pelas mãos calejadas dos trabalhadores do campo. Uma reminiscência possível na pluma de Nação Zumbi (1994): "Que eu me organizando posso desorganizar, que eu desorganizando posso me organizar".

Outro dos debates teóricos que fundamentaram nossa construção foi aquele que nos permitiu reconstruir a relação que existe entre as expressões da questão social e os processos de luta das classes subalternas. Ao enfrentar a questão social a partir de processos coletivos de agregação das massas, estes movimentos abrem novos horizontes para o exercício profissional: as lutas tensionam as correlações de força institucional; colocam novas requisições que desafiam os procedimentos institucionais que individualizam o acesso aos direitos sociais; questionam as rotinas que reproduzem relações clientelistas onde despolitizam e esvaziam a cidadania ${ }^{7}$. As

\footnotetext{
${ }^{6}$ Sobre o projeto de Reforma Agrária Popular o MST afirma: “Ela deve ser popular, porque é fruto da aliança dos trabalhadores rurais e dos trabalhadores urbanos. [...] Ela é popular, porque os interesses dela são o da população, e não os das empresas" (Mazin; Estevam; Stedile, 2016, p. 66). Trata-se de uma reelaboração da proposta clássica de reforma agrária, pela necessidade de atualizar a luta pela terra em novas condições sóciohistóricas. Esta característica que é própria de muitos movimentos que lutam pela terra na América Latina, tem levado os movimentos a pensar outros aspectos que envolvem não apenas a desconcentração fundiária, mas também a preservação dos bens comuns da natureza, a produção de alimentos saudáveis para o conjunto da classe trabalhadora, relações sociais e de trabalho que não reproduzam exploração e opressão, violências patriarcais, dentre outros aspectos.

${ }^{7}$ Referências importantes para este debate podem ser encontradas no documento CFESS Manifesta - O trabalho do assistente social junto aos movimentos sociais. CFESS, Brasília, 2018.
} 
lutas destes movimentos sociais são referências societárias importantes para pensar em um perfil profissional sensibilizado com os processos sociopolíticos de enfrentamento às desigualdades sociais: um profissional de Serviço Social comprometido com o fortalecimento do protagonismo dos sujeitos sociais; capaz de se contrapor aos intentos de despolitização e cooptação que prevalecem nas estratégias de abordagem da questão social na atualidade; apto para reinscrever os serviços sociais públicos no campo dos direitos, retirando-os das práticas clientelistas e de tutela vigentes; contribuindo com a mobilização, a capacitação e o fortalecimento dessas experiências organizativas; socializando informações para a transparência pública dos recursos institucionais; fomentando a criação de espaços públicos que permitam a comunicação, a organização dos trabalhadores que usufruem das políticas sociais e a expressão da insatisfação coletiva como verdadeiros suportes do controle social e institucional ${ }^{8}$.

\section{Adapte, use e reutilize}

Territórios Agroecológicos é um instrumento dinâmico que pretende dialogar com o cotidiano dos trabalhadores rurais através de um universo lúdico, tendo como base as relações sociais, as formas de vida e de trabalho constituídas no dia a dia do seu território. A estrutura do jogo permite que um número considerável de pessoas possa jogar, inclusive em grupos. Elaborado com materiais resistentes, possui um tabuleiro de proporções grandes, confeccionado sobre uma lona preta. Retrata, ao mesmo tempo, as proporções dos latifúndios improdutivos ocupados para a Reforma Agrária e recria símbolos e materiais com os quais o movimento constrói suas primeiras moradias. Nesse tabuleiro, temos as peças utilizadas pelos participantes para avançar nas casas, que são uma espécie de pinos temáticos elaborados simbolicamente a partir de elementos importantes para a reprodução da vida no campo: um chapéu, uma barraca de lona, uma enxada e uma muda. Ademais, o jogo contém um dado; cartões que criam situações específicas relacionadas à luta pela terra; cartões das charadas (muitas das quais foram criadas junto a acampadas/os, recuperando saberes sobre agroecologia); um espaço que contém os recursos, denominado de "Espaço Heranças da Luta", alguns dos quais são distribuídos entre os grupos jogadores para começar a partida: sementes, livros, mudas, máquinas, ferramentas, gados e materiais para construção de casas ou barracos.

Os grupos jogadores se constituem em Núcleos de Base (NB), reproduzindo uma forma utilizada pelo movimento para organizar as famílias em acampamentos e assentamentos. Todos iniciam a partida com a mesma quantidade de recursos: sementes para plantio, ferramentas e máquinas. Outros recursos precisam ser conquistados durante o jogo, como livros para a biblioteca popular, gados e mudas. No decorrer da dinâmica, os NB podem tanto doar, receber ou perder recursos, a depender do cartão de situação ou charada que retirar.

\footnotetext{
${ }^{8}$ Iamamoto (2009); Abreu \& Cardoso (2009); Marro \& Duriguetto (2016).
} 
A grande estratégia do jogo está no fato de não se reduzir apenas a "ganhar ou perder", mas de promover a interdependência entre os NB, envolvendo a possibilidade de ações de solidariedade que melhoram o desempenho ou significam ganhos que têm impactos positivos nos outros grupos. Os acontecimentos no jogo envolvem conquistas e perdas, assim como avanços e retrocessos que são sempre coletivos.

Ao jogar o dado, os NB avançam uma quantidade determinada de casas e a depender da casa em que caírem, retiram um cartão que define a situação. Os cartões foram elaborados, parte em sala de aula na Universidade, e parte no acampamento, para permitir e registrar a troca de saberes. Além de conhecimentos relacionados com a agroecologia e os ensinamentos da luta pela terra, os cartões de situações e charadas trazem símbolos do movimento e conquistas específicas do acampamento Edson Nogueira. Vale destacar que determinados cartões podem ser reelaborados a cada partida, podendo as/os acampadas/os acrescentar outras situações. Determinadas casas são simbólicas e dão emoção ao jogo. Algumas casas exigem tarefas específicas, como recitar poesias ou cantar uma música do movimento; ou envolvem atitudes solidárias com outros NB, com o Espaço Heranças da Luta ou com comunidades próximas do município de Macaé; ou determinam ganhos ou perdas de recursos. Também existem casas que propõem ações de solidariedade com territórios periféricos da região ${ }^{9}$.

Ao final, vence a partida o NB que chegar primeiro à Unidade Pedagógica em Agroecologia. No jogo significa a conquista de um território da Reforma Agrária Popular e um espaço de formação em agroecologia para a classe trabalhadora do campo e da cidade.

\footnotetext{
${ }^{9}$ Interessante observar que um ano depois dessa experiência, já no contexto da crise sanitária provocada pela pandemia, muitos das/os assentadas/os do PDS Osvaldo de Oliveira que participaram do Jogo, seriam os mesmos que protagonizariam ações reais de solidariedade nesses mesmos territórios que aparecem enunciados nos cartões, doando alimentos agroecológicos para reverter a fome e a precarização da vida.
} 
Regras do Jogo

\section{Territórios agroecológicos}

Bem-vindas/os ao Jogo Territórios

Agroecológicos. Este instrumento de Educação Popular é fruto da troca de saberes entre a comunidade do Acampamento Edson Nogueira (Macaé, Rio de Janeiro), Educandas/os da Unidade Pedagógica em Agroecologia e estudantes de Serviço Social do Campus Universitário de Rio das Ostras da Universidade Federal Fluminense. Como o mestre Paulo Freire nos ensinou, este jogo pretende reunir conhecimentos que nascem da cultura e da identidade Sem Terra e se tornam vivos na experiência da luta pela terra tão importante para a região. Aqui se luta pela educação do campo para as crianças e os adultos, aqui se luta por terra e alimentos sem veneno, aqui nos organizamos para conquistar políticas públicas para a população do campo, aqui chamamos outras/os trabalhadoras/es para lutar conosco por um futuro melhor, aqui construímos Territórios Agroecológicos. Venham, cheguem, juntem-se a nós, porque aprender, lutar e brincar são coisas sérias!

\section{O Jogo contém}

1 tabuleiro, 4 pinos temáticos, 1 dado, Cartões de situações, Cartões das charadas, 150 Sementes, 50 Mudas, 50 Ferramentas, 50 gados, 50 Materiais para construção das Casas ou barracos, 50 livros. Sementes, Máquinas e outros recursos encontram-se no "Espaço Heranças da Luta".

\section{O jogo vai começar....}

O jogo pode ser jogado em grupos que serão os núcleos de base (NB). Crianças e adultos podem jogar juntos! Cada núcleo começa o jogo com 20 sementes, 1 máquina e 3 ferramentas do Espaço Heranças da Luta.
Outros recursos serão adquiridos no decorrer do jogo.

Cada núcleo de base joga o dado e o núcleo que tirar o número mais alto começa, sendo seguido pelos outros núcleos com o mesmo critério. Algum/a companheiro/a deve ficar responsável por administrar os recursos do Espaço Heranças da Luta.

\section{Como Jogar}

O núcleo de base vai avançar o número de casas que tirar no dado. Vocês devem obrigatoriamente andar esse número de casas, a menos que vocês passem pelas casas (Entrada de novos membros, festa junina, dia de luta, estratégia de luta), onde vocês devem parar obrigatoriamente.

Sempre mova seu pino para a frente. Se sua movimentação terminar em uma casa na qual já há algum núcleo jogador, vá para a casa livre seguinte. Siga as instruções da casa. Uma vez executada sua tarefa, é a vez do outro núcleo e ao finalizar, jogue o dado novamente para continuar.

\section{Entrada de novos membros no NB}

Todos os jogadores que pararem nesta casa ganham presentes! Jogue o dado para saber quanto ganhará dos outros núcleos

- 1 ou 2 - seu núcleo recebe 3 sementes dos outros NB para os novos membros trabalharem;

- 3 ou 4 - seu núcleo recebe 5 sementes dos outros NB para os novos membros trabalharem;

- 5 ou 6 - seu núcleo recebe 8 sementes dos outros NB para os novos membros trabalharem. 
Festa Junina no Assentamento Osvaldo de Oliveira

Ebaaaa! Dia de Arraiá! Jogue o dado para saber se seu núcleo deverá levar a comida a ser oferecida nas barracas, será responsável pela quadrilha ou será agraciado com o prêmio sorteado ao final da festa!

- 1 ou 2 - seu NB doa a um outro núcleo 5 sementes e 1 gado que representam as comidas das barracas;

- 3 ou 4 - seu NB recebe 3 mudas do Espaço Heranças da Luta porque a quadrilha estava linda! Deve escolher um núcleo para doar 1 muda;

- 5 ou 6 - seu NB recebe 5 gados e 5 livros do Espaço Heranças da Luta porque ganharam o prêmio do sorteio!

Dia de luta

Toda vez que passar ou parar num dia de luta o núcleo tem a opção de: cantar uma música do movimento, ou recitar uma poesia referente à luta, ou criar um grito de ordem. Deixando claro que não poderão repetir a mesma música, poesia ou grito nas próximas casas ou já usadas por outros núcleos.

Dia de conquista

Se parar em um espaço dia de conquista, significa que o núcleo conseguiu produzir o suficiente para adquirir recursos fundamentais! Jogue o dado para saber quanto ganhará do Espaço Heranças da Luta.

- 1 ou 2 - seu NB recebe 1 ferramenta e 1 muda;

- 3 ou 4 - seu NB recebe 2 materiais para construção das casas ou barracos e 1 gado;

- 5 ou 6 - seu NB recebe 2 ferramentas e 5 livros.
Solidariedade de classe

Quando seu núcleo parar em um dos espaços solidariedade de classe, significa que seu esforço é fundamental para ajudar os/as compas! Terá que escolher entre:

- Dar a metade das suas sementes, ou 2 ferramentas ou 1 livro para qualquer um dos outros núcleos;

- Voltar dez espaços para auxiliar suas/seus compas a fazer trabalho de base para uma nova ocupação;

- Doar 5 livros ao último núcleo colocado para criar uma Biblioteca Popular no Bairro Nova Holanda.

\section{O amanhã pertence a nós, Trabalhadores!}

Quando seu núcleo parar em um dos espaços $o$ amanhã pertence $a$ nós, trabalhadores! significa que sua vitória é também a vitória das/os compas! Terá que escolher entre:

- Se tiver um NB mais atrás de vocês, podem escolhê-lo e puxá-lo para avançar uma casa a frente do seu núcleo;

- Se houver um NB que tenha menos sementes que vocês, nesse caso, ele ganha sementes do Espaço Heranças da Luta até ficar com a sua mesma quantidade;

- Vocês e todos os outros NB devem dar 1/3 das suas sementes para manter o Espaço Heranças da Luta.

\section{Estratégia de Luta}

Vocês são obrigados a parar na casa estratégia de luta e nela vocês devem jogar o dado e dependendo do número que sair:

- 1 ou 2 - seu núcleo deve responder um cartão das charadas e se acertar permanece no jogo, mas se perder, fica fora do jogo; - 3 ou 4 - seu núcleo acertou na negociação com o Incra e ganhou 1 livro e 5 ferramentas do Espaço Heranças da Luta; 
- 5 ou 6 - seu núcleo estava colaborando com uma nova ocupação e sofreu um despejo. Deve retroceder 10 casas.

\section{Ao retroceder}

Quando vocês tiverem que voltar o caminho: - Não precisa cumprir as ordens dos espaços que passar ou parar;

- Quando voltar a andar para a frente, todas as ordens passam a valer novamente, exceto entrada de novos membros, festa junina, dia de luta, estratégia de luta.

O que fazer se não tiver recursos para cumprir as tarefas?

Se seu núcleo não tiver recursos é possível adquirir emprestados no Espaço Heranças da Luta mas vocês deverão devolvê-los no decorrer do jogo e antes de passar a casa atravessada pelo córrego. Se ao passar por essa casa não tiver devolvido ou não tiver os recursos para devolver, deverão retroceder:

- Para cada semente, retroceda 1 casa.

- Para cada muda, retroceda 2 casas.

- Para cada gado ou livros retroceda 3 casas.

- Para cada ferramenta ou material de construção retroceda 4 casas.

Quando se ganha o Jogo Territórios Agroecológicos?

- Quando o primeiro núcleo chega na Unidade Pedagógica: é um dia de comemoração! Significa que a terra da Unidade Pedagógica em Agroecologia está nas mãos da comunidade e agora é um território da Reforma Agrária Popular e um espaço de formação em agroecologia para a classe trabalhadora do campo e da cidade.
- Quando houver apenas dois núcleos de base jogando e um deles ficar fora do jogo 


\title{
Reescrevendo a palavra (e o mundo): aprendizados para a formação profissional
}

\author{
O que salva a humanidade é que não há quem cure a curiosidade
}

(Tom Zé, 2014).

Esta experiência formativa e de intervenção nos permitiu ensaiar a construção de outras relações pedagógicas da profissão com os movimentos sociais das classes subalternas. Encontramos no jogo, ou, melhor, na arte de jogar, alguns significados para a nossa atuação profissional, contribuindo também com a qualificação do processo de auto-organização das/os acampadas/os. A escolha pela forma lúdica e coletiva de apreender acerca do significado do acesso à terra; da Reforma Agrária; das formas agroecológicas de plantio; das novas relações produzidas a partir da luta experimentada pelas famílias acampadas, foi também uma aposta por recusar posturas de tutela e subalternização, muitas vezes reproduzida pela Universidade ao se aproximar de movimentos sociais.

Através da experiência, pudemos vivenciar o significado de uma Universidade socialmente referenciada, que articula ensino, pesquisa e extensão, socializando um conjunto de saberes entre trabalhadoras/es e segmentos subalternos que muitas vezes não têm acesso ao direito à educação. Ao mesmo tempo, exercitamos o desafio de incorporar na formação das/os Assistentes Sociais, saberes que emanam das experiências organizativas dos subalternos, as pautas e reivindicações dos movimentos que garantem ou prefiguram direitos sociais fundamentais.

Ao lutar pela terra, o MST evidencia e enfrenta coletivamente, desigualdades sociais que brotam da forma como o agronegócio explora e expropria os meios de vida da população do campo. É por meio da luta que as/os trabalhadoras/es se organizam frente à ausência do poder público trazendo reivindicações de emprego; alimentação saudável; habitação; acesso à educação e à saúde; disputando seus direitos sociais na cena política. Compreender as expressões da questão social a partir dos processos de luta e organização permite observar uma das raízes da demanda profissional, por meio de suas arestas de conflito e resistência, muitas vezes silenciadas nos equipamentos de políticas públicas. A aproximação com esta experiência possibilitou a análise do significado político dos direitos e políticas sociais, dando visibilidade às disputas e contradições que perpassam seu processo de formulação e implementação, produto de relações de força que devem ser decifradas pelo profissional de Serviço Social (Marro \& Duriguetto, 2016).

O contato com um território em luta pela terra exige de profissionais, professores e estudantes, também a compreensão das contradições que atravessam as precárias condições de vida. Por estes motivos, são territórios que não estão livres de reproduzir conflitos e desigualdades, mas assumem o desafio coletivo de construir outras relações sociais. Nessa direção, o Jogo Territórios Agroecológicos funcionou como um instrumento para dialogar de forma lúdica com expressões conservadoras que se manifestam como racismo, machismo ou violências e discriminações contra as populações LGBT. No jogo há várias situações que retratam direitos e ações de solidariedade que enfrentam estas opressões, como por exemplo, um cartão de 
situação que fomenta uma ação de solidariedade no lote de um casal de lésbicas que tem sua plantação ameaçada por fatores climáticos.

O exercício de construção de instrumentos de educação popular nos desafiou a dialogar com as estratégias de formação política construídas pelo movimento, assim como também a valorizar possíveis dimensões da atuação profissional relacionadas com a mobilização e a organização coletiva em torno de necessidades e reivindicações por melhores condições de vida. Colocamos em pauta uma competência profissional tão importante como aquela que afirma: "prestar assessoria e apoio aos movimentos sociais em matéria relacionada às políticas sociais, no exercício e na defesa dos direitos civis, políticos e sociais da coletividade" (CFESS, 1993). Também exercitamos o nosso direito de "apoiar e/ou participar dos movimentos sociais e organizações populares vinculados à luta pela consolidação e ampliação da democracia e dos direitos de cidadania" (CFESS, 1993), presente no Código de Ética das/os Assistentes Sociais.

A articulação do Serviço Social com as lutas e movimentos sociais que enfrentam, através dos seus processos de auto-organização, diversas expressões da questão social contemporânea é um elemento central do nosso projeto éticopolítico, não sempre tão fácil de materializar nas condições atuais do nosso exercício profissional. Por isso é fundamental exercitar esta dimensão socioeducativa ao longo da formação. Dentre outras, se destacam as atividades de educação popular que dialogam com as estratégias de formação política dos próprios movimentos - que buscam a "elevação cultural e intelectual das massas", em termos gramscianos -, ou aquelas orientadas à potencialização da mobilização e da organização coletiva em torno de necessidades e reivindicações por melhores condições de vida. Experiências de estágio (estágios de vivência ou obrigatórios de acordo com as exigências pedagógicas dos cursos) e extensão; cursos de formação política; propostas de assessoria; cursos de especialização; produção de materiais didáticos que socializam informações sobre os direitos e políticas sociais; ou realização de trabalhos de campo a partir de disciplinas de graduação, são alguns dos caminhos que nos permitem vivenciar este vínculo com os movimentos sociais, tão importante para o redimensionamento crítico da profissão.

Reunindo elementos da identidade e da cultura Sem Terra, este instrumento de educação popular motivou a curiosidade, instigando e convidando à criação coletiva - dimensão essencial da prática educativa. Entrar no universo das/os acampadas/os permitiu exercitar a abertura para uma realidade que pode ser distante para alguns estudantes e profissionais do Serviço Social. Nesses territórios, cruzam-se uma variedade de histórias com múltiplos significados, e por isso somos, a todo momento, tensionadas/os a ter uma postura crítica; sensível para captar esse universo; respeitando a autonomia e os processos decisórios construídos pelo movimento; abertas/os a traduzir e tornar acessível conhecimentos que possam enriquecer suas lutas. Olhar para a mão de um/a agricultor/a é, também, senti-la. Andar pelo seu território é, também, tocá-lo. Deixar-se ser conduzido é experimentar a confiança. Formar uma roda e sentar-se sobre a terra ou sobre um tronco para compartilhar conhecimentos, é, também, olhar nos olhos de quem sabe pela experiência. Experimentar o universo do outro - marcado pela vivência da luta pela 
terra, mas também pelo desafio da produção agroecológica - é, sobretudo, rever o próprio universo - e os conhecimentos apreendidos numa Universidade que se enriquece nessa troca. Acampadas/os, estudantes e professoras/es construímos conhecimentos coletivos, dialogando com saberes e elementos de identidade que são fundamentais na organização do movimento - em termos gramscianos, elementos de "cultura popular" que fermentam nas suas lutas. Cantamos, recitamos e brincamos, e vivenciamos um momento de formação diferenciado. Jogar um jogo sério na vida adulta, é recriar uma certa liberdade da infância. E o agricultor/a é, antes de tudo, um forte ${ }^{10}$.

Às e os estudantes de Serviço Social da disciplina Movimentos Sociais e Educação Popular do $1^{\circ}$ semestre de 2019 da UFF de Rio das Ostras.

Às e os acampadas/os do Acampamento Edson Nogueira e assentadas/os do Projeto de Desenvolvimento Sustentável Osvaldo de Oliveira do MST de Macaé, que brincaram conosco.

\section{Referências}

ABREU, Marina Maciel; CARDOSO, Franci Gomes. Mobilização Social e práticas educativas. In: Serviço Social: direitos sociais e competências profissionais. Brasília: CFESS/ABEPSS, 2009. p. 593-608.

BOGO, Ademar. A Mística: parte da vida e da luta. In: PELOSO, Ranulfo (org.).

Trabalho de base (seleção de roteiros organizados pelo Cepis). São Paulo: Editora Expressão Popular, 2012.

CALDART, Roseli. Pedagogia do Movimento Sem Terra. São Paulo: Editora Expressão Popular, 2004.

CONSELHO FEDERAL DE SERVIÇO SOCIAL (CFESS). Código de Ética do/a Assistente Social. 1. ed. Brasília: CFESS, Cap. 4, art. 12. 1993.

CONSELHO FEDERAL DE SERVIÇO SOCIAL (CFESS). Lei no 8.662, de 7 de junho de 1993. Lei de regulamentação da profissão de assistente social. Brasília: CFESS. 1993.

CONSELHO FEDERAL DE SERVIÇO SOCIAL (CFESS). O trabalho do assistente social junto aos movimentos sociais. In: CFESS Manifesta. Brasília 2018. Disponível em: http://www.cfess.org.br/arquivos/2018-CfessManifesta-16Enpess-GTPAbepsssite.pdf. Acesso em: ago. 2019.

CUNHA, Euclides da. Os Sertões. In: CUNHA, Euclides da. Obras completas. 2. ed. Rio de Janeiro: Nova Aguilar, 1995.

DEL ROIO, Marcos (Org.). Gramsci. Periferia e Subalternidade. São Paulo: Edusp, 2017.

\footnotetext{
${ }^{10}$ Paráfrase da célebre frase de "Os Sertões" de Euclides da Cunha "O Sertanejo é, antes de tudo, um forte" (1995, p. 179).
} 
FREIRE, Paulo. Princípios do trabalho popular. In: PELOSO, Ranulfo (org.). Trabalho de base (seleção de roteiros organizados pelo Cepis). São Paulo: Editora Expressão Popular, 2012. p. 21-31

FREIRE, Paulo. Pedagogia do Oprimido, 17. ed. Rio de Janeiro: Editora Paz e Terra, 1987.

GRAMSCI, Antônio. Volume 1: Introdução ao estudo da filosofia. A filosofia de Benedetto Croce. Cadernos do Cárcere. Rio de Janeiro: Editora Civilização Brasileira, 1999.

GRAMSCI, Antônio. Volume 5: O Risorgimento. Notas sobre a história da Itália. In: Cadernos do Cárcere. Rio de Janeiro: Civilização Brasileira, 2002.

GREIN, Maria Izabel. O Movimento Sem Terra, da educação popular à pedagogia do movimento. In: TAVARES, M.T.; ALVARENGA, M.; SILVA, C.A. Educação popular, movimentos sociais e formação de professores. São Paulo: Editora Outras Expressões, 2015. p. 137-154.

IAMAMOTO, Marilda. Os espaços sócio-ocupacionais do assistente social. In: CFESSABEPSS. Serviço Social: direitos sociais e competências profissionais. Brasília: CFESSABEPSS, 2009.

IASI, Mauro. Educação Popular: formação da consciência e luta política. In: SILVEIRA, Maria L. S.; FARAGE, Eblin (Orgs.). Seminário de Educação Popular e Lutas Sociais. Rio de Janeiro: CFCH/UFRJ, 2004.

IASI, Mauro. Ensaios sobre consciência e emancipação. 2. ed. São Paulo: Editora Expressão Popular, 2011.

MARRO, Katia \& DURIGUETTO, Maria Lúcia. Serviço Social, lutas e movimentos sociais: a atualidade de um legado histórico que alimenta os caminhos de ruptura contra o conservadorismo. In: SILVA, Maria Liduína de Oliveira (Org.). Serviço Social no Brasil: história de resistências e de ruptura com o conservadorismo. 1.ed. São Paulo: Cortez, 2016, v. 1, p. 97-118.

MAZIN, Angelo; ESTEVAM, Douglas; STEDILE, Miguel (Orgs.). História do MST: A gente cultiva a terra e ela cultiva a gente. Veranópolis: Instituto de Educação Josué de Castro-ITERRA/UFFS. 2016.

MONTEIRO, Jéssica O. Serviço Social e Educação Popular: contribuições para o debate sobre sua atualidade. 2018. Dissertação (Mestrado em Serviço Social), UFRJ/PPGSS, Rio de Janeiro, 2018.

MORISSAWA, Mitsue. A história da luta pela terra e o MST. 3. ed. São Paulo: Expressão Popular, 2008.

NAÇÃO ZUMBI. Da lama ao caos. Pernambuco: Chaos. 1994 
OUVIÑA, Hernán. Educación Popular y disputa hegemónica. Los aportes de Gramsci para el análisis de los proyectos pedagógico-políticos de los movimientos sociales. In: Observatório social de empresas recuperadas y autogestionadas - OSERA. Buenos Aires, n. 6, 2012. Disponível em:

https://publicaciones.sociales.uba.ar/index.php/osera/issue/view/558. Acesso em: 3 set. 2020.

SEMERARO, Giovanni et al. Gramsci e os movimentos populares. 2. ed. Niterói: Editora da UFF, 2013.

TOM ZÉ. Salva a humanidade. Álbum: Vira lata na via láctea, 2014. 